Journal of Social Sciences 7 (4): 485-494, 2011

ISSN 1549-3652

(C) 2011 Science Publications

\title{
Motivation and Sports Games in the Physical Education Sports Lesson a Student from the University of Medicine and Pharmacy "Carol Davila"
}

\author{
Rachita Carmen and Draganescu Elena \\ Department of Physical Education and Sport, \\ The University of Medicine and Pharmacy "Carol Davila", Bucharest
}

\begin{abstract}
Problem statement: At the behavioral manifestation of acts of physical education class at university is motivation. Purpose: Modeling the characteristics of personality and motivation of medical student's development following the establishment of an appropriate methodology to act in university physical education lessons by developing and implementing a strategic program included in organization, management and conduct training process-education, the means of action gamespecific sports: Basketball, handball and volleyball. Approach: Study method bibliographic information, teaching observation, investigation method and experimental method, statistical and mathematical method. In different situations created by practicing sports games shows a different reactivity of the students. Motivation explains why a behavioral act may have a special significance for a student, while the other has a meaning very weak, sometimes absent altogether. The mechanisms regulating behavior of students who practice sports games have motivation that makes important link meaning actions of regulatory systems. One can say that motivation as a key feature of competition, combining dynamic factor activity various elements that go to most intimate corners of the human being. The dimensions of motivation include: goal setting, pulse power, perseverance, hope of success, fear of failure, independence and status oriented. Results and Conclusions: Following testing of the AMI at endpoint for experiment group compared with control group was found to increase motivation of following variables: competitive orientation (4.19), fearlessness (3.39), safety success (3.29) preference for difficulty (3.21), self-control and self-discipline (3.05). Fundamental components of the game sports (technique, tactics, individual and collective actions) are a complex structure means that it acts on motoric behavior, psycho-motor and the task-oriented motivation towards achieving goals, motivation to element of time and self-determination of students. Recommendations: Experimenting new curricula to the educational process of physical education students of medical, dental and pharmacy, adapting its content according to themes, can lead to the sample improvements in parameters tested experimentally.
\end{abstract}

Key words: Physical education, sports games, research hypothesis, educational process, regulatory systems, mathematical method, task effort, collective actions, parameters tested

\section{INTRODUCTION}

Motivation medical students develop during the course of the educational process in university physical education classes. The term motivation is derived from the Latin word that means moving mover. Therefore, the essence of motivation is the desire for change, the opposite of staying in the same state. Motivation developed by Abraham Maslow theory is based on a hierarchy of needs. In his basement needs to be met before it goes to higher satisfaction. Some of the theory of Maslow's higher needs can be met by engaging in specific activities and university physical education implied by practicing sports games. Hierarchy of needs (Maslow) is useful in explaining the motivation, especially because it demonstrates the difficulty of focusing on higher needs, such as competence or selfrealization when basal needs are properly met. McClelland-Atkinson model supports two basic psychological constructs which retain their value until today. The first is the construct of intrinsic motivation or what McClelland and Atkinson call motivation to achieve success and the second construct is what they call anxiety or fear of failure. Atkinson said that-the

Corresponding Author: Rachita Carmen, Department of Physical Education and Sport,

The University of Medicine and Pharmacy "Carol Davila", Bucharest 


\section{J. Social Sci., 7 (4): 485-484, 2011}

study of personality is not only the most ambitious, but also the oldest area of interest within psychology (Atkinson and Hilgard, 2005).

The type is one attraction-rejection, meaning that the subject considered the decision to engage in an activity (nearby) or to withdraw (rejection). Everything depends on the strength or size of the two psychological constructs. If a competitive situation the motivation for students to achieve success is stronger than fear of failure, they will be tempted to engage in that situation. Conversely, if the fear of failure is stronger than the desire to participate (intrinsic motivation), they will avoid. In its simplest form, the model is represented by the formula: $\mathrm{P}=\mathrm{Mj}-\mathrm{Fe}$, where $\mathrm{P}=$ participation, $\mathrm{I}=$ intrinsic motivation, fear of failure $\mathrm{Fe}$. In this study we address various aspects of motivation and its relationship with self-confidence, goals orientation, allocation theory, the choice of objectives in physical education and sport. Maslow believes that internal needs are more pressing than others and the need for basic needs (the lower levels) prior to release energy required for higher order fulfillment needs (Maslow, 1987).

The way students relate to themselves is directly related to the perception that it has on the causes and effects of their actions. The types of assignments that students are normally reveal their motivational structure. Furthermore, the influence that we can provide them with specific means for sports games to change their perceptions could have a significant effect on motivation to succeed. The predictive efficacy of sport motives may well vary from competitive periods to noncompetitive periods and this would hold important implications for theory development (Bhatnagar et al., 2008). As a result, motivation and theory are closely related award. For example, young students tend to attribute failure to lack of innate abilities. Because these skills are relatively permanent, it is difficult for them to believe that things will ever change for the better. However, if these young students would be influenced in university physical education classes to assign physical existence of sustained success, they could feel at one point that things can be changed. Thus, students will be associated with task orientation that success depends on effort and improvement. Task-oriented students tend to initiate adaptive motivational patterns. This means that students choose to participate in challenging situations that allow them to demonstrate their ability and persistence in task effort. The Achievement Motivation Inventory (AMI) is a personality inventory designed to measure a broad construct of work-related achievement motivation. Achievement motivation is a personality variable that has been used to explain individual differences in a number of practical contexts: school, sports and the world of work. It was built on a new concept of how a wide variety of facets of achievement motivation are interrelated with each other. Many of the facets incorporated into the AMI are similar to traditional aspects of personality. For the first time the AMI integrates relevant social motives into a test measuring the construct of achievement motivation as well. Thus, in addition to traditional scales, e.g. Confidence in Success or Persistence, scales like Dominance or Status Orientation are integrated in the AMI. According to Zeng et al. (2010), The PTs are college students who are currently studying in PETE programs. They intend to become physical education teachers at K-12 school levels. They must complete the student teaching requirements at K-12 school levels in order to graduate from a university/college.

Orientation itself reflects the fact that success depends on a student's performance compared with the performance of other students. So, ability is seen regardless of effort. Thus, a student self-oriented, success in sports practice means overcoming an opponent's game because of superior skills and not supported or autoperfecționarii effort. Students who have a higher perception of their abilities, can develop adaptive motivational patterns. Psychosocial factor, which include psychological risk factor refers to individual's perception of the job characteristics which can promote positive feedback (motivation and satisfaction) and stress. (Samad et al., 2010). Research has shown that individuals with a predominant orientation to task orientation can manifest itself very sharp. A number of research conducted in rural sports orientation stresses the superiority of pregnancy. Regarding the objectives, there are two distinct orientations: task orientation and self orientation. If task-orientation, the objective is the improvement of techniques or skills. Task-oriented students perceive their skills depending on progress in physical education lessons on the axis between two successive moments of time (t1performance is obtained when compared with that from the time $\mathrm{t} 2$ ).

In the game of basketball athlete is task-oriented students perceive themselves as having superior skills that made a better percentage than the free throws were made a week ago. A coach who is having $3 \mathrm{~h}$ basketball practices could schedule the more difficult and higher risk activities in the first half of practice and leave the lower risk activities for the last hour when the athletes will be feeling the effects of fatigue and this problem must care in athletes with chronic ankle instability (Hosseinimehr et al., 2010). Based on the findings of the present research, it was conclude that there is 


\section{J. Social Sci., 7 (4): 485-484, 2011}

significant difference between some of the kinematic parameters of successful and unsuccessful kick to definite targets. This discrepancy in female was observed more at the before the impact phase and in men at the time of impact, maximum values and follow through phase (Gheidi and Sadeghi, 2010).

Students who are more task-oriented games continue to practice sport-specific means to achieve such skills and experience feelings of autoeficacitate and confidence. for orientation to themselves perceive ability depends largely on the outcome of comparison between the performance of others. Important to develop self-confidence and success are the existence of pregnancy masterly execution. For a student to feel confident in his abilities during the course of games the national sports competitions (Cup or the Cup years I "Carol Davila") must first successful experiment in university physical education lessons. Develop selfconfidence is related to students' task persistence and their willingness to make substantial efforts to improve.

Despite muscular fatigue, ankles appear to be more stable after exercise. Does exercise induce an increase in afferent/efferent nerve impulses to and from muscle spindles around the ankle leading to improved joint position sense? It is suggested that handball and basketball players perform proprioception drills both in the rested and exercised state (Letafatkar et al., 2009). In fact, thoughts influence emotions, which in turn influences the behavior or performance: Thoughts Emotions - Performance. A student may not feel selfconfident in a particular case, contrary to available skills. Lack of confidence will have a negative effect on the performance of its sporting prowess. The frequency of the sprains in the AFC is higher in males-athletes than in females occurred more in the sports of basketball, track and field, volley ball and soccer. The PE teachers of the AFC should be given emphasis in the stretching techniques that might include in the warming up and cooling dawn sessions. Also, the conditions of playing surfaces should be improved in order students/athletes to compete in a safe and healthy environment. Finally, PE teachers should exert better supervision and guidance of students/athletes during trening (Tyflidis et al., 2009).

During physical education lessons in preparation for sporting prowess university students there is a feature Trust named sports personality and a certain orientation toward competition. These two factors are predictive of specific situational sport confidence that students show a sports game during practice.

Premise: The experimental research on the proposed theme we started from the premise that only through a specific means of efficiently operated sports games in university physical education lesson, we can capture a variety of phenomena, expressed by specific systemic relationships that can act synergistically in an interdisciplinary vision for optimization, development of the motivation behind the professional performance of medical students.

Purpose: Identifying new approaches to scientific research on the development of medical students' motivation and drive to establish the methodology by developing and implementing new programs in organizing, directing and conducting the educational process in university physical education class, which contains specific means games sports basketball, volleyball and handball.

Objectives: The objectives are subordinated to establish theoretical and practical bases of information reflecting the fundamental science of physical education and sport, in order to demonstrate the need to address the concept of sports games in the context of the instructive educational system to develop medical students' motivation.

\section{These include:}

- Identifying necessary psycho diagnosis finding the psychological profile of students

- Identifying the profile of each student motivation inventory using Achievement Motivation Inventory (AMI)

- Identify and implement the most effective elements, processes, resources and specific technical and tactical methods sports games, which is operational objectives in the educational process for students to establish a working methodology scientifically

- Develop a means to influence specific sports games effective motivation in medical students

- Development by practicing sports games, motivation on task orientation, towards the goals

- motivation to achieve success, motivation and time as an element of student self-determination

Hypothesis: Inductive hypothesis can be synthesized from the idea that the development of motivation on task orientation, towards the goals, motivation to achieve success, motivation and time as an element of student self-determination may be the consequence of the use of appropriate and effective means specific games sports, appropriate dosage and iterated motivation for each of the features such as: Persistence, dominance, 
engagement, safety, success, flexibility, absorption, fearlessness, energy clearing, self, self, status orientation, competition orientation and goal setting.

Deductive hypothesis we can formulate saying that:

- If you associate the technical and tactical methods and means of sports games in the educational process as an original program, specially developed and applied scientifically new features can influence the motivation of medical students

- If recourse to knowledge of the psychological profile of medical students on motivation to achieve targets, task orientation, self-determination and motivation as an element of lasting scientific approach can accelerate the effective driving directions scales with small values of characteristics AMI motivation

- If team sports games are played with the final successful attack and defense, due to the specific means of action in basketball, handball and volleyball where it can produce positive effects on student motivation and may lead to socioprofessional inclusion of future doctors

- If there is a strong motivation for practicing sports games when it is due to students' implicit personality

Research variables: Independent variables represented by means of specific sports games are manipulated in order to determine the effects they have on the development of student motivation. Dependent variables-characteristics of motivation - after operation by the application program means specific sports games in physical education lesson raises the question factors that appear in the research hypothesis, which we anticipate a change of some kind, a direct result of the influence of independent variables.

Research tasks: Experimental research tasks are subordinated to the purpose and consist of:

- Organizing fund information to substantiate the theoretical and methodological

- Develop working hypotheses

- Selection of research facilities and drive effective educational process-education, the independent experimental variables

- Establish sample experiment and control groups

- Develop specific methods and experimentation program sports games in the learning process through action-education of physical education lesson on groups of students
- Assess the quality and effectiveness of the program implemented by the data recording

- $\quad$ Storage and processing of recorded data

- Analyze and interpret results

- Directing, controlling and evaluating the learning process - the education of the university physical education classes in order to enhance student motivation in medicine

- Development of general and practical conclusions

\section{METRIALS AND METHODS}

In the process of scientific investigation was used the following methods:

- Method study bibliographic information

- Analysis and synthesis of the literature.

- Pedagogical method of observation

- Observation Psycho-Pedagogical

- Direct observation

- Transverse observation

- Longitudinal observation

In experimental research, we used direct observation carried out during physical education classes. Transversal observation was made simultaneously delving into groups by age, year of study and sex, about their favorite sports games and physical education lesson observation longitudinal research has allowed evolution in time, consisting of monitoring driving behavior, psychomotor and psychological students since I observed that continued in the second year students at the University of Medicine and Pharmacy "Carol Davila"-Bucharest:

- Survey method

- Questionnaire survey-Motivation questionnaire AMI-Achievement Motivation Inventory

- Interview

- Survey

- The experimental method

- $\quad$ Statistical-mathematical method

Experiment content: Program development strategy was the focus of the typical medical student's motivation, the particular, the needs and interests and life experience. This special program developed by means of specific sports games to be a creator of life experiences, including professional, building a sense in which each student finds his way motivational development of task-orientation towards the achievement of goals .towards self-determination and to achieve success by acting on the environment in which they work, but also on himself. 


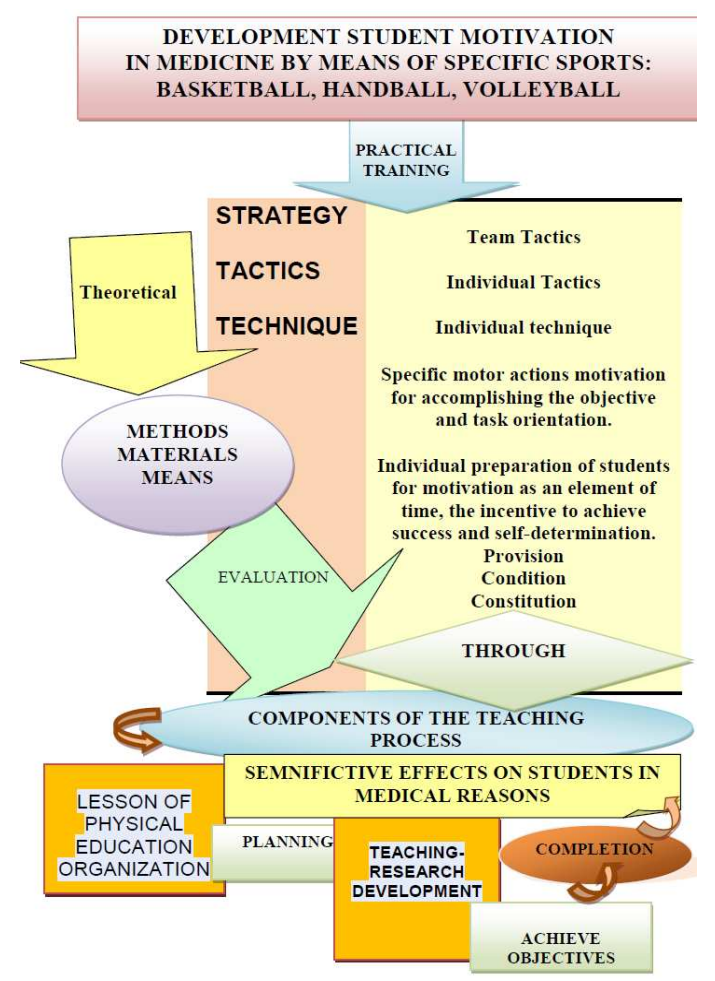

Fig. 1: Strategic Vision for the implementation of the experimental program

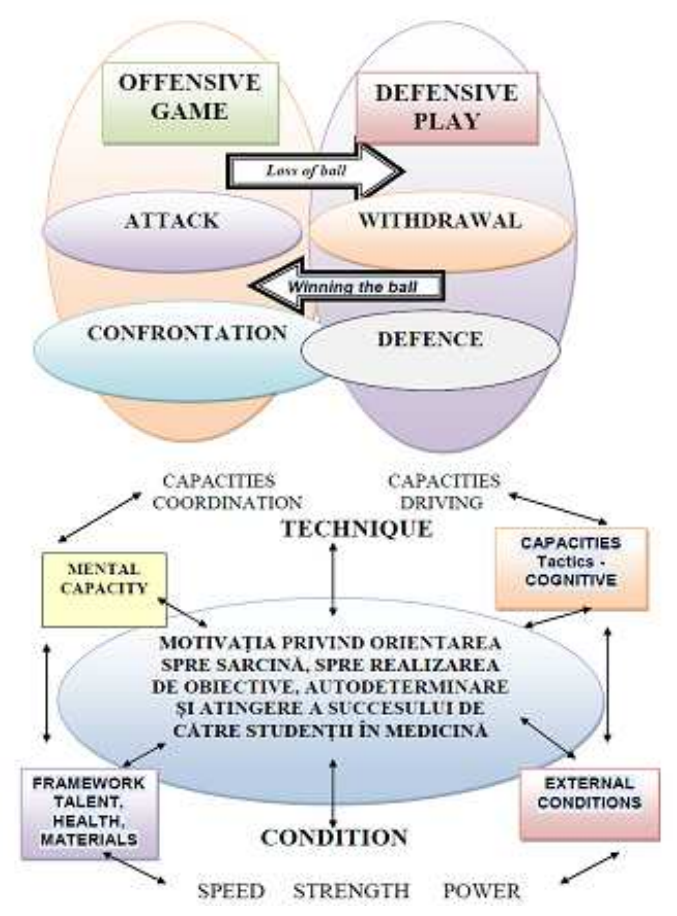

Fig. 2: Systemic vision of game play model that determine the motivation

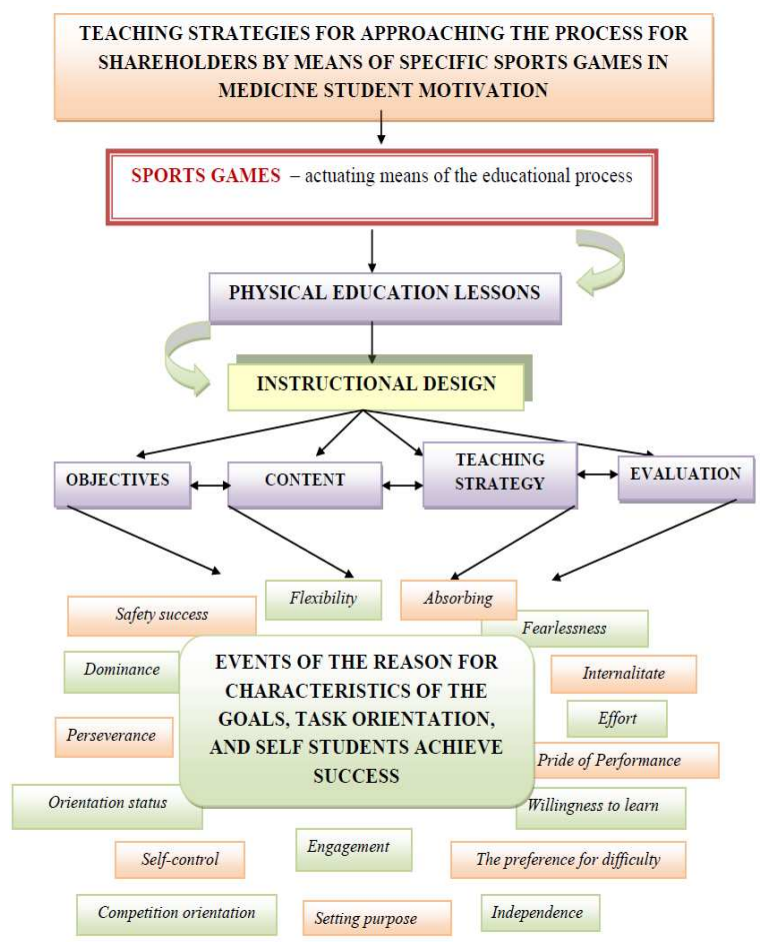

Fig. 3: Representation systemic pedagogical model proposed for physical education lesson to drive the sports games on the motivation to achieve the objectives, orientation to task, achieve success and self-determination of medical students

The program is specifically designed to work in field education at the University of Medicine and Pharmacy "Carol Davila". Here is a working knowledge of medical students in relation to personality education, taking into account specific knowledge of the person who has a globally unique identity and the constituent subsystems: Physical, psychological - and sociocultural behavior. Pedagogic model and teaching strategy development and implementation of the experimental program to develop medical students' motivation through specific sports games are shown schematically as apparent in Fig. 1-3.

\section{RESULTS}

Answers to the 170 items of psychological test AMI-Achievement Motivation Inventory was introduced in SPSS 15.0 (Statistical Package for the Social Sciences), resulting in a profile of student motivatieifiecarui. To find out the Motives of 120 students representing the final structure of experimental research sample we calculated the average, median and standard deviation at baseline and at endpoint for each variable and for each student. 
J. Social Sci., 7 (4): 485-484, 2011

Table 1: Presentation of data from inventory management Acievement Motivation Inventory (AMI)

\begin{tabular}{|c|c|c|c|c|c|c|c|c|c|c|}
\hline \multirow{3}{*}{$\begin{array}{l}\text { Reasons variables } \\
\text { Time of testing }\end{array}$} & \multicolumn{8}{|c|}{ Statical indicators } & & \\
\hline & \multicolumn{2}{|c|}{ Arithematic } & \multicolumn{2}{|c|}{ Standard deviation } & \multicolumn{2}{|c|}{ Standard error } & \multicolumn{2}{|c|}{ Coefficient of variation } & \multicolumn{2}{|l|}{$\mathrm{T}$ test } \\
\hline & Initial & Final & Initial & Final & Initial & Final & Initial & Final & t calc. & $\mathrm{t}$ tab. \\
\hline Perseverence (BF) & 4.72 & 6.33 & 1.51 & 1.55 & 0.14 & 0.14 & 31.96 & 31.96 & 8.290 & 1.980 \\
\hline Dominance (DO) & 5.23 & 7.16 & 1.53 & 1.32 & 0.14 & 0.140 & 29.30 & 29.30 & 29.00 & 1.98 \\
\hline Commitment (EN) & 6.30 & 7.53 & 1.29 & 1.25 & 0.12 & 0.120 & 20.54 & 20.54 & 17.68 & 1.98 \\
\hline Safety success (EZ) & 5.63 & 7.38 & 1.78 & 1.46 & 0.16 & 0.160 & 31.61 & 31.61 & 18.89 & 1.98 \\
\hline Flexibility (FX) & 4.41 & 6.38 & 1.60 & 1.60 & 0.15 & 0.150 & 36.20 & 36.20 & 28.43 & 1.98 \\
\hline Absorbing (FL) & 5.18 & 6.02 & 1.61 & 1.75 & 0.15 & 0.150 & 36.20 & 36.20 & 28.43 & 1.98 \\
\hline Fearlessness (FU) & 3.99 & 6.22 & 1.55 & 1.75 & 0.14 & 0.140 & 38.77 & 38.77 & 27.01 & 1.98 \\
\hline Internalitate (IN) & 3.97 & 6.15 & 1.47 & 1.85 & 0.16 & 0.160 & 43.84 & 43.84 & 29.55 & 1.98 \\
\hline Compensator effort (KA) & 5.77 & 7.27 & 1.44 & 1.45 & 0.13 & 0.130 & 25.01 & 25.01 & 17.25 & 1.98 \\
\hline Pride of performance (LS) & 5.85 & 6.41 & 1.68 & 1.67 & 0.15 & 0.150 & 28.69 & 28.69 & 3.36 & 1.98 \\
\hline Willingness to learn (LB) & 5.57 & 7.51 & 1.22 & 1.17 & 0.11 & 0.110 & 21.94 & 21.94 & 27.23 & 1.98 \\
\hline $\begin{array}{l}\text { The preference } \\
\text { for difficult (SP) }\end{array}$ & 5.33 & 7.40 & 1.74 & 1.4 & 0.16 & 1.960 & 32.59 & 32.59 & 29.57 & 1.98 \\
\hline Independence (SE) & 5.43 & 4.26 & 1.53 & 2.06 & 0.14 & 0.140 & 28.20 & 28.2 & 9.27 & 1.98 \\
\hline $\begin{array}{l}\text { Self-control and } \\
\text { self discipline (SK) }\end{array}$ & 5.33 & 6.65 & 1.46 & 1.56 & 0.13 & 0.130 & 27.35 & 27.35 & 19.74 & 1.98 \\
\hline Status orientation (ST) & 6.28 & 8.08 & 1.42 & 1.19 & 0.13 & 0.130 & 22.62 & 22.62 & 18.65 & 1.98 \\
\hline $\begin{array}{l}\text { Competition } \\
\text { orientation (WE) }\end{array}$ & 2.77 & 8.31 & 1.42 & 1.08 & 0.13 & 0.130 & 24.60 & 24.6 & 28.47 & 1.98 \\
\hline Goal setting (ZE) & 6.24 & 7.72 & 1.47 & 1.16 & 0.13 & 0.130 & 23.59 & 23.59 & 17.46 & 1.98 \\
\hline
\end{tabular}

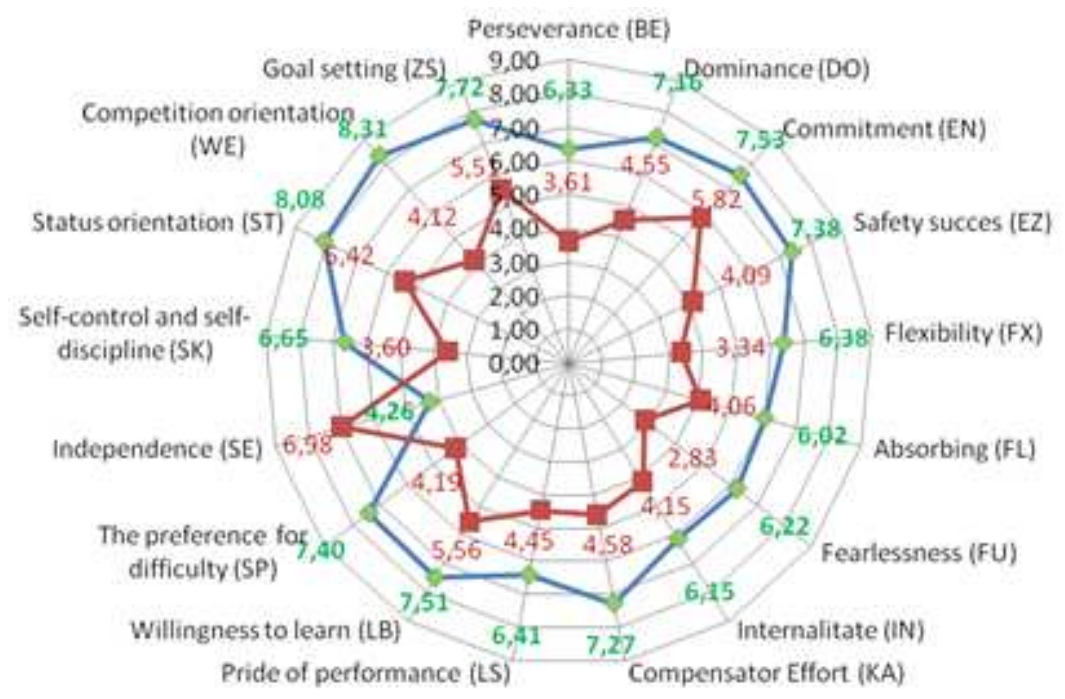

Fig. 4: Graphical representation of the typical medical student profile for the

The coefficient of variation of standard deviation results from dividing the average inventory of each variable for each student's motivation as shown in Table 1.

Following testing of the AMI at endpoint for the experiment group compared with control group, was found to increase the motivation of the following variables: Competitive orientation (4.19), fearlessness (3.39), safety success (3.29) preference for difficulty (3.21), self-control and self-discipline (3.05). The only scale that has been declining AMI is independence (-2.72) as shown in Fig. 4.
Variables specific motivation inventory AMI: Fundamental components of the game sports (technique, tactics, individual and collective actions) Is a complex structure means that it acts on motoric behavior, psycho-motor and thus the task-oriented motivation towards achieving goals, motivation to element of time and self-determination of students. These funds are exposed to modern teaching methods of organizing and conducting physical education lessons and sports, the typical student in medicine is always in relationship with oneself and with others. 


\section{J. Social Sci., 7 (4): 485-484, 2011}

Table 2: Overview of changes in motor and psycho-motor test and experimental research program implicate

\begin{tabular}{|c|c|c|c|c|c|c|c|}
\hline \multirow[b]{2}{*}{ Sports game } & \multirow[b]{2}{*}{ Test name } & \multirow[b]{2}{*}{ Test indicators } & \multicolumn{5}{|c|}{ Experimental group } \\
\hline & & & $\begin{array}{l}\text { Initial } \\
\text { testing }\end{array}$ & $\begin{array}{l}\text { Final } \\
\text { test }\end{array}$ & $\begin{array}{l}\text { Calculated } \\
\mathrm{T}\end{array}$ & $\mathrm{T}$ critic & $\alpha$ \\
\hline \multirow{12}{*}{$\begin{array}{l}\text { Technical training testing } \\
\text { basketball }\end{array}$} & \multirow[t]{4}{*}{ Chamber test } & Dribbling through comer seconds & 15.77 & 13.63 & 15.94 & 2.2 & 0.05 \\
\hline & & Baskets marked (Number) & 12.62 & 17.01 & 14.00 & 2.2 & 0.05 \\
\hline & & Jumping to recovery & 8.10 & 7.43 & 14.00 & 2.2 & 0.05 \\
\hline & & Passing of the chest (sec) & 23.30 & 21.48 & 13.90 & 2.2 & 0.05 \\
\hline & \multirow[t]{4}{*}{ Harison test } & Successful baskets $(30 \mathrm{sec})$ & 5.63 & 8.83 & 53.91 & 2.2 & 0.05 \\
\hline & & Passing contretempts ( $30 \mathrm{sec})$ & 21.73 & 24.74 & 37.34 & 2.2 & 0.05 \\
\hline & & Milestones completed $(30 \mathrm{sec})$ & 18.35 & 21.73 & 39.15 & 2.2 & 0.05 \\
\hline & & Rebounds panel basket ball $(30 \mathrm{sec})$ & 22.26 & 24.66 & 14.77 & 2.2 & 0.05 \\
\hline & \multirow[t]{4}{*}{ Leilich test } & Dribing basket scored seconds & 4.59 & 2.60 & 12.66 & 2.2 & 0.05 \\
\hline & & Basket scored within 30 seconds & 6.93 & 10.84 & 44.00 & 2.2 & 0.05 \\
\hline & & Scorring pass with two hands on the wall & 50.63 & 54.69 & 41.19 & 2.2 & 0.05 \\
\hline & & Baschetball efficiency index & 0.10 & 0.31 & 4.52 & 2.2 & 0.05 \\
\hline \multirow{4}{*}{$\begin{array}{l}\text { Technical training testing } \\
\text { handball }\end{array}$} & \multirow[t]{4}{*}{ Technical probe } & Dribbling through comes (sec) & 22.45 & 18.88 & 37.86 & 2.2 & 0.05 \\
\hline & & Passing the ball to the wall (number) & 19.71 & 23.94 & 33.54 & 2.2 & 0.05 \\
\hline & & Handball complex (sec) & 0.75 & 0.64 & 7.46 & 2.2 & 0.05 \\
\hline & & Handball efficiency index & 0.09 & 0.40 & 10.34 & 2.2 & 0.05 \\
\hline \multirow{3}{*}{$\begin{array}{l}\text { Technical training testing } \\
\text { volleyball }\end{array}$} & Brady test & Kicks valid-volleyball (number) & 12.06 & 13.09 & 14.77 & 2.2 & 0.05 \\
\hline & Petry test & Supplemental bottom side top (number) & 9.22 & 11.23 & 35.54 & 2.2 & 0.05 \\
\hline & High wall test & sending the ball in the target area (number) & 1.43 & 1.35 & 36.06 & 2.2 & 0.05 \\
\hline \multirow{2}{*}{$\begin{array}{l}\text { Psyco-motric test } \\
\text { preparation baskerball } \\
\text { handball and volleyball }\end{array}$} & J.L. fountain test & Psycomotor test (sec) & 1.71 & 1.68 & 13.21 & 2.2 & 0.05 \\
\hline & $\begin{array}{l}\text { C. Rachita } \\
\text { psychomotor }\end{array}$ & $\begin{array}{l}\text { Psychomotoric assessment: dynamic } \\
\text { coordination laterality perceptual motor }\end{array}$ & 19.92 & 23.25 & 23.95 & 2.2 & 0.05 \\
\hline \multirow{2}{*}{$\begin{array}{l}\text { Testing speed and agility } \\
\text { Basketball and volleyball }\end{array}$} & Adams test & Jumping errors number & 7.68 & 5.72 & 7.58 & 2.2 & 0.05 \\
\hline & 505 test & Speed (sec) & 2.94 & 2.89 & 8.35 & 2.2 & 0.05 \\
\hline \multirow[t]{2}{*}{ Physical test preparation } & Small marathon & Resistance seconds & 25.83 & 33.61 & 18.57 & 2.2 & 0.05 \\
\hline & $\begin{array}{l}\text { Shuttle cars } \\
\text { for ball }\end{array}$ & Speed strength coordination (seconds) & 33.39 & 31.55 & 15.19 & 2.2 & 0.05 \\
\hline $\begin{array}{l}\text { Testing focusing attention } \\
\text { basketball and volleyball }\end{array}$ & Labyrinth test & $\begin{array}{l}\text { Capacity consternation the spirit of } \\
\text { observation visual acuity (No of poients) }\end{array}$ & 4.56 & 7.27 & 17.90 & 2.2 & 0.05 \\
\hline $\begin{array}{l}\text { Preoperational test reaction } \\
\text { basketball handball volleyball }\end{array}$ & sociometric test & Coefficient of group cohension & 0.16 & 0.67 & 9.99 & 2.2 & 0.05 \\
\hline
\end{tabular}

Table 2: Continue

\begin{tabular}{|c|c|c|c|c|c|c|c|}
\hline \multirow[b]{2}{*}{ Sports game } & \multirow[b]{2}{*}{ Test name } & \multirow[b]{2}{*}{ Test indicators } & \multicolumn{5}{|c|}{ Control group } \\
\hline & & & $\begin{array}{l}\text { Initial } \\
\text { testing }\end{array}$ & $\begin{array}{l}\text { Final } \\
\text { test }\end{array}$ & $\begin{array}{l}\text { Calculated } \\
\mathrm{T}\end{array}$ & $\mathrm{T}$ critic & $\alpha$ \\
\hline \multirow{12}{*}{$\begin{array}{l}\text { Technical training testing } \\
\text { basketball }\end{array}$} & \multirow{3}{*}{ Chamber test } & Dribbling through comer seconds & 14.37 & 15.4 & 9.71 & 1.98 & 0.05 \\
\hline & & Baskets marked (Number) & 9.32 & 9.0 & 3.25 & 1.98 & 0.05 \\
\hline & & Jumping to recovery & 10.95 & 14.03 & 11.30 & 1.98 & 0.05 \\
\hline & \multirow{5}{*}{ Harison test } & Passing of the chest (sec) & 23.38 & 23.03 & 2.51 & 1.98 & 0.05 \\
\hline & & Successful baskets ( $30 \mathrm{sec})$ & 6.67 & 6.61 & 0.57 & 2.20 & 0.05 \\
\hline & & Passing contretempts $(30 \mathrm{sec})$ & 21.63 & 21.21 & 3.08 & 1.98 & 0.05 \\
\hline & & Milestones completed ( $30 \mathrm{se})$ & 18.74 & 17.91 & 4.88 & 1.98 & 0.05 \\
\hline & & Rebounds panel basket ball ( $30 \mathrm{sec})$ & 24.58 & 23.64 & 5.71 & 1.98 & 0.05 \\
\hline & \multirow[t]{4}{*}{ Leilich test } & Dribing basket scored $(\mathrm{sec})$ & 5.58 & 5.20 & 1.88 & 1.98 & 0.05 \\
\hline & & Basket scored within $30 \mathrm{sec}$ & 5.87 & 5.68 & 1.70 & 1.98 & 0.05 \\
\hline & & Scorring pass with two hands on the wall & 50.84 & 49.54 & 5.68 & 2.57 & 0.05 \\
\hline & & Baschetball efficiency index & 0.09 & 0.07 & 2.55 & 2.20 & 0.05 \\
\hline \multirow{4}{*}{$\begin{array}{l}\text { Technical training testing } \\
\text { handball }\end{array}$} & \multirow[t]{4}{*}{ Technical probe } & Dribbling through comes $(\mathrm{sec})$ & 23.58 & 23.32 & 2.15 & 2.20 & 0.05 \\
\hline & & Passing the ball to the wall (number) & 20.12 & 19.58 & 2.90 & 2.20 & 0.05 \\
\hline & & Handball complex seconds & 0.75 & 0.78 & 2.33 & 1.98 & 0.05 \\
\hline & & Handball efficiency index & 0.09 & 0.07 & 2.55 & 2.57 & 0.05 \\
\hline \multirow{3}{*}{$\begin{array}{l}\text { Technical training testing } \\
\text { volleyball }\end{array}$} & Brady test & Kicks valid-volleyball number & 10.68 & 9.49 & 18.60 & 2.20 & 0.05 \\
\hline & Petry test & Supplemental bottom side top number & 8.92 & 8.04 & 14.92 & 2.20 & 0.05 \\
\hline & High wall test & sending the ball in the target area (number) & 8.04 & 6.43 & 12.26 & 2.20 & 0.05 \\
\hline \multirow{3}{*}{$\begin{array}{l}\text { Psyco-motric test } \\
\text { preparation basketball } \\
\text { handball and volleyball }\end{array}$} & J.L. fountain test & Psychomotor test (sec) & 1.42 & 1.45 & 9.91 & 2.20 & 0.05 \\
\hline & C. Rachita & Psychomotoric assessment: dynamic & 1.96 & 1.97 & 1.24 & 2.20 & 0.05 \\
\hline & psychomotor & $\begin{array}{l}\text { coordination laterality perceptual motor } \\
\text { coordination speed of movement }\end{array}$ & 18.39 & 17.95 & 4.05 & 2.20 & 0.05 \\
\hline \multirow{2}{*}{$\begin{array}{l}\text { Testing speed and agility } \\
\text { Basketball and volleyball }\end{array}$} & Adams test & Jumping errors number & 8.39 & 9.05 & 8.64 & 2.20 & 0.05 \\
\hline & 505 test & Speed seconds & 3.04 & 3.35 & 4.46 & 2.20 & 0.05 \\
\hline \multirow[t]{2}{*}{ Physical test preparation } & Small marathon & Resistance seconds & 36.80 & 37.03 & 1.44 & 2.20 & 0.05 \\
\hline & $\begin{array}{l}\text { Shuttle cars } \\
\text { for ball }\end{array}$ & Speed strength coordination $(\mathrm{sec})$ & 34.19 & 34.53 & 4.99 & 2.20 & 0.05 \\
\hline $\begin{array}{l}\text { Testing focusing attention } \\
\text { basketball and volleyball }\end{array}$ & Labyrinth test & $\begin{array}{l}\text { Capacity consternation the spirit of } \\
\text { observation visual acuity (No of points) }\end{array}$ & 4.63 & 4.24 & 8.60 & 2.20 & 0.05 \\
\hline $\begin{array}{l}\text { Preoperational test reaction } \\
\text { basketball handball volleyball }\end{array}$ & sociometric test & Coefficient of group cohesion & 0.18 & 0.18 & 0.75 & 2.57 & 0.05 \\
\hline
\end{tabular}


Table 2: Continue

\begin{tabular}{|c|c|c|c|c|c|c|}
\hline \multirow[b]{2}{*}{ Sports game } & \multirow[b]{2}{*}{ Test name } & \multirow[b]{2}{*}{ Test indicators } & \multicolumn{4}{|c|}{ ANOVA } \\
\hline & & & $\mathrm{df}_{1}$ & $\mathrm{df}_{2}$ & Calculated F & $\mathrm{T}$ critic \\
\hline \multirow{12}{*}{$\begin{array}{l}\text { Technical training testing } \\
\text { basketball }\end{array}$} & \multirow{3}{*}{ Chamber test } & Dribbling through comer seconds & 1 & 238 & 16.10 & 3.88 \\
\hline & & Baskets marked (Number) & 1 & 238 & 163.28 & 3.88 \\
\hline & & Jumping to recovery & 1 & 238 & 688.92 & 3.88 \\
\hline & & Passing of the chest (sec) & 1 & 238 & 11.63 & 3.88 \\
\hline & \multirow[t]{4}{*}{ Harison test } & Successful baskets $(30 \mathrm{sec})$ & 1 & 238 & 23.87 & 3.88 \\
\hline & & Passing contretempts $(30 \mathrm{sec})$ & 1 & 238 & 28.81 & 3.88 \\
\hline & & Milestones completed $(30 \mathrm{sec})$ & 1 & 238 & 54.74 & 3.88 \\
\hline & & Rebounds panel basket ball $(30 \mathrm{sec})$ & 1 & 238 & 2.74 & 3.88 \\
\hline & \multirow[t]{4}{*}{ Leilich test } & Dribing basket scored $(\mathrm{sec})$ & 1 & 238 & 99.08 & 3.88 \\
\hline & & Basket scored within $30 \mathrm{sec}$ & 1 & 238 & 117.28 & 3.88 \\
\hline & & Scorring pass with two hands on the wall & 1 & 238 & 4.23 & 3.88 \\
\hline & & Basketball efficiency index & 1 & 238 & 7.77 & 3.88 \\
\hline \multirow{4}{*}{$\begin{array}{l}\text { Technical training testing } \\
\text { handball }\end{array}$} & \multirow[t]{4}{*}{ Tehnical probe } & Dribbling through comes $(\mathrm{sec})$ & 1 & 238 & 57.27 & 3.88 \\
\hline & & Passing the ball to the wall (number) & 1 & 238 & 63.80 & 3.88 \\
\hline & & Handball complex seconds & 1 & 238 & 17.54 & 3.88 \\
\hline & & Handball efficiency index & 1 & 238 & 51.39 & 3.88 \\
\hline \multirow{3}{*}{$\begin{array}{l}\text { Technical training testing } \\
\text { volleyball }\end{array}$} & Brady test & Kicks valid-volleyball (number) & 1 & 238 & 85.60 & 3.88 \\
\hline & Petry test & Supplemental bottom side top number & 1 & 238 & 102.85 & 3.88 \\
\hline & High wall test & sending the ball in the target area (number) & 1 & 238 & 141.53 & 3.88 \\
\hline Psyco-motric test & J.L. fountain test & Psycomotor test (sec) & 1 & 238 & 152.42 & 3.88 \\
\hline $\begin{array}{l}\text { preparation basketball } \\
\text { handball and volleyball }\end{array}$ & $\begin{array}{l}\text { C. Rachita } \\
\text { psychomotor }\end{array}$ & $\begin{array}{l}\text { Psychomotoric assessment: dynamic } \\
\text { coordination laterality perceptual motor } \\
\text { coordination speed of movement }\end{array}$ & 1 & 238 & 29.43 & 3.88 \\
\hline \multirow{2}{*}{$\begin{array}{l}\text { Testing speed and agility } \\
\text { Basketball and volleyball }\end{array}$} & Adams test & Jumping errors number & 1 & 238 & 36.35 & 3.88 \\
\hline & 505 test & Speed seconds & 1 & 238 & 34.67 & 3.88 \\
\hline \multirow{2}{*}{ Physical test preparation } & Small marathon & Resistance seconds & 1 & 238 & 27.08 & 3.88 \\
\hline & $\begin{array}{l}\text { Shuttle cars } \\
\text { for ball }\end{array}$ & Speed strength coordination (sec) & 1 & 238 & 39.69 & 3.88 \\
\hline $\begin{array}{l}\text { Testing focusing attention } \\
\text { basketball and volleyball }\end{array}$ & Labyrinth test & $\begin{array}{l}\text { Capacity consternation the spirit of } \\
\text { observation visual acuity (No of poients) }\end{array}$ & 1 & 238 & 131.80 & 3.88 \\
\hline $\begin{array}{l}\text { Preoperational test reaction } \\
\text { basketball handball volleyball }\end{array}$ & sociometric test & Coefficient of group cohension & 1 & 238 & 74.46 & 4.96 \\
\hline
\end{tabular}

If the context motoric behavior develops when the motivation will be positively influenced in the same direction.

Following trials carried out at sports games: Basketball, handball and volleyball has improved driving test results for experimental group students used the final test when compared to initial testing, as shown in Table 2 which shows the calculation of statistical indicators.

\section{DISCUSSION}

In almost all cases, tcalc> ttab, which shows that the null hypothesis (H0) is rejected and accepted alternaltiva hypothesis (H1) and that all the samples at the final moment of the experiment, the results of the students plan and motor and psychomotor have improved following the application program means specific sports games. The degree of homogeneity from the average $(\mathrm{CV})$ was unchanged from the initial to final testing. In all samples the coefficient is $<35.0 \%$, which means that the samples have a high degree of homogeneity, that spread is small and that media is a significant indicator for the results.
The highest values we have variables: Competitive orientation (8.31), status-oriented (8.08), goal setting (7.72), commitment (7.53), desire for learning (7.51) preference for difficulty (7.40) and safety success (7.38). The student is facing competition (8.31), tending to live competition as an incentive, the comparison with other while searching. Variable value commitment (7.53) shows that the typical medical student, studying a lot and not feeling well when he has nothing to do. Even after very tedious phase, it does not require long recovery periods. It is possible to neglect other important sides of life, for study and work in the chosen occupation.

Desire for learning (7.51) shows an openness to acquiring new knowledge that broaden knowledge. It can be said that high value orientation status (8.08), indicating that the typical medical student can be described as making efforts to hold an important role in the social field and a prominent place in the social hierarchy, seeking to obtain social recognition of professional performance. Goal setting variable value (7.72) makes a clear reference to the future and operational. Students typically sets its goals, is facing challenges for the future and is what he wants to accomplish and achieve. The development of 


\section{J. Social Sci., 7 (4): 485-484, 2011}

motivation characteristic "safety successful" (7.38) indicates that the student wishes to reach the goal, including new or difficult tasks. Perseverance (6.33) has a value somewhere near the middle and can be interpreted by the fact that the typical medical student has a lack of focus of attention at a given time and energy maintaining always enough.

Lower values of the variables are flexibility (6.38), fearlessness (6.22), internalitate (6.15). Variable fearlessness, indicates fear of failure and can be considered negative. Tension is high in the face of tasks, activities or important situations. Also, this shows that young students exhibit emotional instability and inability to work under pressure disturbances having lasting failures, leading to disruptions in the ability to achieve job performance. Low value of flexibility shows that the typical medical student is not open and does not feel the need for change, thereby recognizing a conceptual relationship with introversion.

\section{CONCLUSION}

Personality is a fundamental dimension of human beings and an essential factor of progress in fundamental science and Physical Education in all other areas and the study aims to decipher the complexity of her personality characteristics, to find methods and techniques for stimulation, modeling and recovery of their superior. In a world in which many resources are depleting rapidly, the characteristics of human personality is practically inexhaustible resources, enhance and use them to educate medical students, future specialists in the medical field is not only a personal need for each in part, but also a social need.

Experimenting new curricula to the educational process of physical education students of medical, dental and pharmacy, adapting its content according to themes, led to the sample improvements in the parameters tested experimentally. The physical training tests, the final results grow by an average of 33.61 , the most important occurring in the small long-distance running marathon, where $(\mathrm{t}=18.57, \mathrm{p}<0.05)$, the technical evidence Basketball The test chambers, where t was calculated to test the highest value "Dribbling through cones against time" and the difference is statistically significant with $\mathrm{p}<0.05$ between control group and the control subjects had the result that the final physical training better and also the psycho-motor parameters is presented general and specific, the final test, significant values ( $\mathrm{p}<0.05,0.001, \mathrm{n}-1)$, which demonstrates that students have become research subjects psycho-motor skills necessary future profession. Experimental program effectiveness was demonstrated by analyzing samples of statistical index motility, psycho-motility, speed, agility and physical evidence. In this experimental group subjects had higher indices obtained from control subjects to test the final group at a threshold $\mathrm{p}<0.005$, with a mean of $95 \%$. Test new indicators for assessing motricitații and those proposed for evaluating psihomotricitaţii, new assay specifically designed and conducted to investigate the psychodiagnosis psychological characteristics of personality and motivation are scientific results that come from among young people who have chosen to conduct studies in the medical field.

Sports games were for students an attractive form for carrying out the practical lessons of physical education which provided a special concern of the students to achieve our scientific approach. We believe that providing a full training new doctors, physical education, the specific means of which highlight the role of sports games full personal development work in particular on those aspects of temperament (dinamicoenergy), nature (relational-value), skills (skills performanţiale) and attitudes. Strengthening of personality characteristics constitute an act of great importance since physicians operating in unpredictable environments by the presence of numerous situations of extreme difficulty which are professional subject, especially in emergency surgery, times to be act with a sense of responsibility, self control, intellectual efficiency, courage, perseverance, dedication, attention focusing. We have listed only some of the characteristics of personality that is reflected in the work of the future specialist in medicine.

Approach: We recommend this because students know the motivation behind human performance and provides the opportunity to explain individual differences in behavior. The academic activity in physical education lesson and not least within the profession motivation dictates how students work. Games used sport as a means of basic university physical education lessons such as Basketball, Handball, Volleyball, can be applied in preparing students to enhance motivation with psychological tests at baseline and final, given that only an interdisciplinary approach to tasks on the sides helps bio-physio-psycho-social.

\section{REFERENCES}

Edward, E.S., F. Barbara, L. Geoffrey and N.H. Susan, 2005. Atkinson and Hilgard, Introduction to psychology. 14th Edn., Thomson: Wadsworth, ISBN-10: 0005834252, pp: 800 
Bhatnagar T., 2008. Motives for Sport Participation as Predictors of Motivation Outcomes in Track and Field: A Self-Determination Theory Perspective. Sport J.

Gheidi, N. and H. Sadeghi, 2010. Kinematic comparison of successful and unsuccessful instep kick in indoor soccer. Am. J. Applied Sci., 7: 13341340. DOI: 10.3844/ajassp.2010.1334.1340

Hosseinimehr, S.H., H. Daneshmandi and A.A. Norasteh, 2010. The effects of fatigue and chronic ankle instability on dynamic postural control. Physics Int., 1: 22-26. DOI: 10.3844/PISP.2010.22.26

Letafatkar, K., M.H. Alizadeh and M.R. Kordi, 2009. The effect of exhausting exercise induced fatigue on the double-leg balance of elite male athletes. J. Soc. Sci., 5: 445-451. DOI: 10.3844/JSSP.2009.445.451c
Maslow A.H., 1987. Motivation and Personality. 3rd Edn., Harper and Row, New York, ISBN: 0060419873, pp: 293.

Samad, N.I.A., H. Abdullah, S. Moin, S.B.M. Tamrin and Z. Hashim, 2010. Prevalence of low back pain and its risk factors among school teachers. Am. J. Applied Sci., 7: 634-639. DOI: 10.3844/AJASSP.2010.634.639

Tyflidis, A., A.K. Travlos, A. Tripolitsioti, G. Giannopoulos and A. Stergioulas, 2009. Epidemiology of strains in greek facilitation classes. J. Med. Sci., 9: 208-213.

Zeng, H.Z., R.W. Leung and M. Hipscher, 2010. An examination of teaching behaviors and learning activities in physical education class settings taught by three different levels of teachers. J. Soc. Sci., 6: 18-28. DOI: 10.3844/JSSP.2010.18.28 